\title{
Mueller, Martin, and Bill Parod, project leads.
}

\section{WordHoard. App.}

Evanston, IL: Northwestern University, 2004. Accessed 9 February 2018. wordhoard.northwestern.edu/userman/index.html.

If digital philology needs a founding father, my candidate is Martin Mueller. An Emeritus Professor of English and Classics at Northwestern University, Mueller has done more than anyone else to promote computational research on the language of classical, medieval, and early modern texts. WordHoard, a Java application he released in 2004 "for the close reading and scholarly analysis of deeply tagged texts" ("Index"), offers these tools to "scholarly but nontechnical users [to] explore the [...] query potential of textual data" ("What is WordHoard?"). And despite its lack of updates since 2013, the program remains viable in 2018.

Words are the core of WordHoard: namely, the works of Homer, Hesiod, and the Homeric Hymns (in Greek and in English and/or German), Chaucer, Spenser, and Shakespeare. Every word of these texts has been tagged with its morphological data (lemma, part of speech, word class, major word class, and spelling); its narrative data (whether words are narrated or spoken; and for some texts, the speaker's name, gender, and whether they are mortal or supernatural); its form (in prose or in verse); its metrical shape (for Greek texts); its date of publication; and its definition (for Chaucer's texts).

All of this word-level metadata is as useful as the researcher needs it to be, but WordHoard's "Analysis" menu makes it straightforward to do processes like comparing frequencies, comparing texts, and tracking forms over time. These preset tools are one of WordHoard's greatest strengths. Because they have a gentle learning curve, they make many of the capabilities of natural-language processing available to novice users.

For instance, if you want to compare the vocabulary of a single Shakespeare play with that of his entire corpus, it is a simple matter of selecting a menu item and ticking a few boxes to generate a table that reveals which words (or rather, lemmas) he uses most or least frequently in a given play, compared to the reference population of his complete works. This "log-likelihood analysis" reveals far more than lists of lemmas most frequently used in a text; it reveals which lemmas are used more and less often than would be expected in that text, compared to that reference: e.g., one play compared to all of his other plays. You 
can just as easily compare his histories with his comedies, or his plays with his sonnets, or his male to his female speakers, or his texts published before 1603 to after. If these preset divisions are insufficient for the user's inquiries, they can create a "work set" for further analysis: say, to compare parts of a text with other parts; or everything published by Spenser and Shakespeare in 1590 with 1591; or they can create a "word set" to compare, say, words spoken in Shakespeare's histories in prose with those spoken in comedies in prose.

Yet one need not have a research question in mind, or deform the texts into statistical tables, to find WordHoard valuable and interesting. Users who simply want to analyze texts by reading and exploring queries as they arise, will find a customizable interface that allows them to move nimbly through texts. Information about each word-e.g., its part of speech, its lemma, its frequency, and its variant forms-is a keystroke away. Keyword-in-context (KWIC) searches are a familiar and powerful capability; but WordHoard enables users to search the four text corpora using twenty criteria, each with its own controls. For instance, you can list all the adverbs spoken by mortals in Spenser's Faerie Queene, or all the occurrences of words in Chaucer that begin with the letter " $\mathrm{z}$ ". Results are displayed in a concordance window that groups KWIC lines by work, date, or other customizable criteria; the bottom half of the window displays the lines in question. The result is an elegantly designed, flexible workbench capable of displaying a reading copy of a work (the analysis text) alongside this concordance window (compiling the reference texts).

It's also worth mentioning that WordHoard is open to developers-not through an API, but by offering up all of its source code, its raw data files, its MySQL binary database files, and other files. They are not in a GitHub repository, but are downloadable with a little work. Comprehensive documentation is available, and support is an e-mail away.

A final caveat: WordHoard was released before the Folger Digital Texts edition of Shakespeare was published, so it is based instead on the 1866 Globe Shakespeare, the best machine-readable text available in 2003. This is hardly a fair criticism; in a few years the electronic text of the Oxford Edition of the Collected Works of Edmund Spenser will render WordHoard's use of the 1932-49 Johns Hopkins edition of Spenser obsolete, too. ${ }^{3}$ No doubt someday WordHoard's use of the 1987 Riverside Chaucer (3rd edition) will be superseded. I am less 
qualified to judge the classical editions and translations, whose dates range from 1793 to 2005 . Ultimately, my caveat is an endorsement of the project's future. Because scholars need WordHoard to serve us well beyond its fifteenth birthday, it will need to revisit and periodically update its editions.

In a footnote in 2008, Mueller quotes a response from Harold Bloom to Mueller's letter announcing WordHoard: "I am a throwback and rely entirely on memory in all my teaching and writing." The rest of us will have to rely on what Mueller calls "digital surrogates" to see features of these texts "that you could not discover by just reading [them]" ("Metadata"). Those who are humbler than Bloom are all the wiser.

MICHAEL ULLYOT

University of Calgary

Stringer, Gary A., gen. ed.

DigitalDonne: The Online Variorum, vol. 6.

Greenville, NC: East Carolina University, 1995. Accessed 31 January 2018. donnevariorum.tamu.edu/.

The text on the first page of this major digital resource for studying Donneand for studying early modern poetry and manuscript culture more generallybegins "DigitalDonne constitutes volume 1 of The Variorum Edition of the Poetry of John Donne." This defines quite exactly what DigitalDonne seeks to do, if you know the Donne Variorum well. But its significance will not be evident otherwise, and many readers may find this resource odd in not being focused on Donne's writing in the way they might expect; it is certainly not intended as an online edition of Donne's poetry. Though the volume 1 program is most significant as a component of the Donne Variorum, this resource is still important on its own; at this point in its development, it is also doing something rather different from the original plan for that volume, something that makes very productive use of the digital medium to extend that plan.

Volume 1 of the Donne Variorum was always described (in the volumes published to date, somewhat more than half of the projected total) as an introduction, with no texts, and two major parts: a general commentary on Donne reception and a general textual introduction. The other volumes in the 